\title{
Papillomavirus Protein E2
}

National Cancer Institute

\section{Source}

National Cancer Institute. Papillomavirus Protein E2. NCI Thesaurus. Code C20053.

A viral DNA binding protein involved in viral replication. It is a transcriptional activator and

major regulator of viral DNA replication and gene expression. May interact with p53 in vivo. (from Oncogene 1999;18:7748-54) 